\title{
A RETRADUÇÃO COMO ESPAÇO DA TRADUÇÃO ${ }^{1}$
}

\author{
Antoine Berman \\ Centre Jacques Amyot \\ Tradução de \\ Clarissa Prado Marini* \\ Universidade Federal de Santa Catarina \\ Marie-Hélène C. Torres** \\ Universidade Federal de Santa Catarina
}

\begin{abstract}
O tema dessa intervenção é: a retradução como espaço da tradução. Por "espaço" é preciso entender aqui espaço de sucesso. Nesse
\end{abstract}

\footnotetext{
${ }^{1}$ Artigo publicado na revista Palimpsestes em 1990. A presente tradução foi autorizada para ser publicada em português por Christine Raguet (editora-chefe da revista) e por Isabelle Berman, às quais agradecemos imensamente. Referência bibliográfica completa do artigo original: BERMAN, Antoine. "La retraduction comme espace de la traduction". In: Palimpsestes. N. 4. Presses Sorbonne Nouvelle, Paris: 1990. Disponível em: http:// palimpsestes.revues.org/596 Acesso em: nov 2016.

* Clarissa Prado Marini Doutoranda em Estudos da Tradução - PGET, Universidade Federal de Santa Catarina - UFSC. Possui Bacharel em Letras-Tradução-Francês pela Universidade de Brasília - UnB. Mestra em Estudos da Tradução - POSTRAD, Universidade de Brasília. Universidade Federal de Santa Catarina. Florianópolis, Santa Catarina, Brasil. E-mail: clarissamarini@gmail.com

** Marie-Hélène C. Torres Possui Pós-Doutorado pela Universidade de Minas Gerais (2011), Doutorado em Estudos em Tradução - Katholieke Universiteit Leuven (2001), Mestrado em Literatura pela Universidade Federal de Santa Catarina (1995) e Licenciatura Dupla Português-Francês pela Universidade Federal de Santa Catarina (1992). É Professora Associada da Universidade Federal de Santa Catarina onde atua na graduação em Letras Estrangeiras e no Programa de Pós-Graduação em Estudos da Tradução. Universidade Federal de Santa Catarina. Florianópolis, Santa Catarina, Brasil. E-mail: marie.helene.torres@gmail.com
} 
campo de essencial insucesso que caracteriza a tradução, somente as retraduções podem atingir - de tempos em tempos - o sucesso.

Normalmente, busca-se o fundamento da necessidade das retraduções num fenômeno bem misterioso: enquanto os originais permanecem eternamente jovens (não importando o grau de interesse que se tenha por eles, sua proximidade ou seu distanciamento cultural), as traduções "envelhecem". Correspondendo a um estado determinado da língua, da literatura, da cultura, acontece que, muitas vezes de maneira bem rápida, elas não respondem mais ao estado seguinte. É preciso então retraduzir, pois a tradução existente não desempenha mais o papel de revelação e de comunicação das obras. Além disso - e numa direção de pensamento muito diferente - como nenhuma tradução pode pretender ser "a" tradução, a possibilidade e a necessidade da retradução estão inscritas na própria estrutura do ato de traduzir. Toda tradução feita depois da primeira tradução de uma obra é então uma retradução.

É preciso retraduzir porque as traduções envelhecem e porque nenhuma é $a$ tradução: assim vemos que traduzir é uma atividade submetida ao tempo e uma atividade que tem uma temporalidade própria: a da caducidade e do inacabamento.

Todas essas reflexões são justas, mesmo partindo de fenômenos que não são tão evidentes quanto se pretende: por que uma tradução envelhece? Por que uma obra autoriza várias traduções? As razões citadas não esgotam o caráter enigmático desses fenômenos. Pois enquanto o princípio que quer que uma obra não possa envelhecer não morrer nem sofrer nenhuma exceção, o princípio segundo o qual uma tradução envelhece e morre, conhece exceções significativas: a História nos mostra que existem traduções que perduram tanto quanto os originais e que, às vezes, têm mais brilho que estes. Essas traduções são o que convencionou-se chamar de grandes traduções.

A Vulgata de São Jerônimo, a Bíblia de Lutero, a Authorized Version são grandes traduções. Mas também o são o Plutarco de Amyot, as Mil e uma noites de Galland, o Shakespeare de Schlegel, a Antígona de Hölderlin, o Dom Quixote de Tieck, o Paraíso 
Perdido de Milton por Chateaubriand, o Poe de Baudelaire, o Baudelaire de Stefan George: eis uma lista, não exaustiva, de grandes traduções. Que não envelhecem. Mesmo se o número de leitores suscetíveis a ler a Vulgata tenha reduzido, esta continua - como dizem Valery Larbaud, Julien Green e Meschonnic, cada um à sua maneira - uma tradução inigualável. Mesmo se a Bíblia de Lutero deva ser às vezes "modernizada”, ela também continua sem igual. Mesmo se Plutarco não nos fascine mais, a tradução de Amyot continua viva.

Tirando o fato de que elas não envelheceram, é possível encontrar em todas essas traduções, realizadas em épocas diferentes, em línguas diferentes, com princípios e objetivos diferentes, um ou mais elementos comuns, permitindo indicar precisamente por que elas são "grandes"? Podemos dar um conteúdo concreto à categoria de grande tradução?

Certamente.

Podemos enumerar - e nesse âmbito não podemos fazer mais do que isso hoje - vários traços cuja única coexistência permite uma "grande tradução".

- Esta é inicialmente um evento na língua de chegada, tanto escrita quanto oral.

- Ela se caracteriza por uma extrema sistematicidade pelo menos igual à do original.

- Ela é o lugar de um encontro entre a língua do original e a língua do tradutor.

- Ela cria uma intensa ligação com o original, que é medida pelo impacto que esta tem sobre a cultura receptora.

- Ela constitui um precedente incontornável para a atividade de tradução contemporânea ou anterior.

- Essas traduções têm mais um traço em comum: são todas retraduções.

- Se toda retradução não é uma grande tradução (!), toda grande tradução é uma retradução. 
Para que essa correlação seja empiricamente verdadeira, é preciso nuançá-la de duas maneiras.

Primeiro, ela não é... absoluta. Pode haver uma primeira tradução que seja uma grande tradução. Mas longe de invalidar nossa correlação, essa possibilidade significa somente que a primeira tradução foi colocada inicialmente como uma retradução e isso cada vez segundo modalidades particulares.

Em seguida, é preciso detalhar o próprio conceito de retradução. Esta não qualifica apenas toda nova tradução de um texto já traduzido. Tomemos, para ilustrar isso, o exemplo de Plutarco de Amyot. Esse tradutor retraduziu Plutarco. Mas esse autor, mesmo já tendo sido traduzido em francês, o foi apenas parcialmente e, via de regra, a partir do latim ou do italiano. Amyot de certa maneira fez uma primeira tradução de Plutarco. Primeira em relação aos outros textos, dentre eles, alguns que não tinham sido traduzidos, primeira em relação à língua de partida, o grego. Apesar disso, podemos falar aqui de retradução, já que há uma nova tradução de uma obra, mesmo se uma parte da obra ainda não tivesse sido traduzida. Basta que um texto de um autor já tenha sido traduzido para que a tradução dos outros textos deste autor entre no espaço da retradução. É por essa razão que o Poe de Baudelaire é uma retradução.

Uma vez que o conceito de retradução foi tão ampliado, constataremos que todas as grandes traduções que mencionei são retraduções.

Agora, por que toda grande tradução é necessariamente uma retradução? Ou, ao contrário, por que toda primeira tradução nunca é (ou quase nunca é) uma grande tradução?

Um primeiro elemento de resposta pode ser dado por Goethe que, em seu Divã ocidental-oriental, apresenta três modos de tradução que são na verdade épocas de tradução. O primeiro modo, ou a primeira época, é a tradução intra ou justalinear (palavra por palavra) visando no máximo dar uma ideia grosseira (nas palavras de Goethe) do original. O segundo modo é a tradução livre, que adapta o original à língua, à literatura, à cultura do tradutor. O terceiro modo 
é a tradução literal, no sentido de Goethe, ou seja, a que reproduz as "particularidades" culturais, textuais, etc. do original. Cada vez que uma cultura se lança na aventura da Tradução, segundo Goethe, ela percorre necessariamente esse ciclo. A partir disso fica evidente que nenhuma primeira tradução pode ser uma grande tradução. E na medida em que os dois últimos modos pressupõem o primeiro, é claro que uma tradução bem-sucedida só pode acontecer a partir do segundo modo, ou seja, já de uma "primeira" retradução...

O esquema triádico de Goethe corresponde grosso modo à dialética do Idealismo alemão, segundo a qual, como disse Novalis uma vez, "todo começo é desajeitado". É necessário todo o caminho da experiência para conseguir uma tradução consciente dela mesma. Toda primeira tradução é desajeitada: se repete aqui no nível histórico o que acontece com todo tradutor: nenhuma tradução é uma "primeira versão".

Nessa visão de Goethe, há algo de muito profundo: a saber que toda ação humana, para ser bem-sucedida, precisa da repetição. E isso vale particularmente para a tradução, enquanto que ela já é originalmente uma operação de redobramento, de duplicação. A repetitividade primeira do traduzir é por assim dizer redobrada na tradução. É no momento posterior de uma primeira tradução cega e hesitante que surge a possibilidade de uma tradução bem-sucedida.

Mas esse pensamento de Goethe não esgota a questão, talvez porque ela se baseia numa percepção global do agir humano e não da estrutura da tradução em particular.

Podemos abordar a problemática da retradução de uma maneira não usual e a partir de dois "fatos" fundamentais. Chamaremos eles de kairos e insuficiência. Toda tradução é insuficiente, ou seja, entrópica, quaisquer que sejam seus princípios. Isso quer dizer que: toda tradução é marcada pela "não-tradução". E as primeiras traduções são aquelas que são mais tocadas pela não-tradução. Tudo acontece como se as forças antitradutórias que provocam a "insuficiência" fossem, aqui, todas poderosas. Se a insuficiência, isto é simultaneamente a incapacidade de traduzir e a resistência ao traduzir, afeta todo ato de tradução, há entretanto uma temporali- 
dade desse ato (temporalidade tanto psicológica quanto cultural e linguística) que faz com que seja em seu início (na primeira tradução) que a insuficiência está em seu máximo. A retradução surge da necessidade nem tanto de suprimir, mas pelo menos de reduzir a insuficiência original. A tradução de uma obra entrou então no espaço da retradução. Isso se manifesta primeiramente por uma multiplicidade de novas traduções e cada uma, à sua maneira, se confronta com o problema da insuficiência (é atualmente o caso de Shakespeare, de Leyris a Bonnefoy e Déprats). Às vezes, nessa multiplicidade, aparece uma grande tradução que, por um tempo, suspende a sucessão das retraduções ou diminui sua necessidade. Na grande tradução, a insuficiência continua presente, mas contrabalanceada por um fenômeno que podemos chamar, com os tradutores do século XVI, a copia, a abundância. Na retradução bem-sucedida reina uma abundância específica: riqueza da língua, extensiva ou intensiva, riqueza da relação com a língua do original, riqueza textual, riqueza significante, etc. De fato, a grande tradução nos impõe um outro discurso sobre a tradução além do, tradicional, da perda: o discurso da abundância. Essa abundância surge primordialmente da reiteração que constitui a retradução. E tanto as primeiras traduções são "pobres", marcadas pela perda, quanto a grande retradução se posiciona sob formas diversas sob o signo da profusão superabundante.

Mas para que se produza essa tradução abundante, é preciso outra coisa, o kairos, o momento favorável. A grande retradução só surge "no momento favorável". O momento favorável é aquele no qual se encontra bruscamente e imprevisivelmente (mas não sem razões) a resistência "suspensa" que gera a insuficiência, a incapacidade de traduzir "bem" uma obra. O kairos não se limita aos parâmetros socioculturais que facilitam, ou até permitem, a tradução de uma obra. Pois estes permitem somente, para retomar a distinção de Meschonnic, a introdução de uma obra (sua translação). Não sua tradução no sentido radical do termo.

Categoria temporal, o kairos remete à própria História. Num dado momento torna-se "finalmente" possível traduzir uma obra. 
Depois de muitas introduções eruditas, escolares, muitas adaptações, torna-se possível inscrever a significância de uma obra em nosso espaço linguístico. Isso acontece com um grande tradutor que se define pelo impulso tradutor que não é o simples desejo de traduzir. Todo tradutor deseja traduzir (em princípio!). Mas esse desejo, em si, se conjuga com seu oposto, o desejo de não traduzir, ou mais precisamente, o recuo frente ao ato de traduzir. Pode-se destacar muito bem, numa tradução, os recuos de um tradutor. Mas naquele em que o impulso tradutor habita, o recuo está reduzido ao mínimo: Lutero, Amyot, Schlegel, Armand Robin são exemplos luminosos de indivíduos dominados pelo impulso de traduzir.

E esses indivíduos só aparecem quando o tempo da tradução de uma obra chegou, ou retornou. Esse tempo (re)torna quando, para uma cultura, a tradução de uma obra se torna vital para seu ser e sua história. Naturalmente, isso só poderia ser, de novo, uma retradução. Pois é preciso que, de sua parte, a obra tenha amadurecido longamente sua presença em nós, para que a necessidade de sua retradução apareça. O quão pouco tem a ver o kairos com as determinações literárias ou socioculturais de superfície, é o que mostra uma das grandes traduções francesas do século XX, a Enei$d a$ de Klossowski. Pois, na superfície, não podemos dizer que a retradução de Virgílio obedecia a uma necessidade para a cultura francesa dos anos 60! Mas, em profundidade, acontece de outra forma: é justamente no momento em que a cultura francesa reflete novamente sobre a relação do muthos, com a épos, que aparece essa tradução. No momento em que se descobre mais precisamente a relação do muthos e do logos, aparece uma tradução literalizante da Eneida, que faz ressoar ou quer fazer ressoar o Dizer épico em francês. E dez anos antes foi publicado quase simultaneamente em alemão, em inglês e em francês a obra de Broch, La Mort de Virgile [A morte de Virgílio]. Não é tudo: na própria história da constituição da cultura literária francesa, a Eneida desempenhou um papel fundamental. É um dos livros antigos que mais foi traduzido e imitado no século XVI. No momento em que a cultura francesa procurou se reconectar com suas origens - o Barroco, o 
Renascimento, a Idade Média - surge uma tradução que, com um tipo de certeza inconsciente, reconecta com o livro que, no tempo de suas origens, exerceu uma fascinação sem igual. Ainda não é tudo: no momento em que acaba na França uma longa tradição etnocêntrica e hipertextual da tradução, o trabalho de Klossowski procura fundar, de maneira certamente provocante, uma nova figura da tradução francesa. Vocês verão que: nessa retradução, o kairos histórico está presente em toda parte. A própria essência da retradução aparece aí de maneira reluzente: reconectar com um original recoberto por suas introduções, restituir sua significância, reunir e desabrochar a língua tradutora no esforço de restituir essa significância, tirar, pelo menos em partes, essa insuficiência da tradução que ameaça eternamente toda cultura.

Recebido em: 07/12/2016

Aceito em: 25/01/2017

Publicado em maio de 2017 